\title{
Logistics Management Issues for Military Systems approaching the End of Service Life
}

\author{
$\underline{\text { Gregory D. Sherman }}^{a}$, Nicholas Brealey ${ }^{a}$, Dana Pietsch $^{a}$, and Stephen Baker $^{a}$ \\ ${ }^{a}$ Defence Science \& Technology Group, Land Division, (LV\&S) Land Logistics \\ Email: gregory.sherman@dsto.defence.gov.au
}

\begin{abstract}
Many concepts and models have been proposed and implemented to support the logistics management of physical assets through their service life. These concepts and models generally focus on a 'steady state' or 'mature' phase of the idealised asset life-cycle, and as such make a number of appropriate simplifying assumptions. As an asset approaches the end of its service life many of these assumptions become questionable and new logistics and fleet management issues begin to arise which potentially require the consideration of new concepts and models. A military system fleet approaching the end of its service life will continue to need ongoing support, which potentially includes support in operations. For this, fleet managers need to continue to invest in inventory to meet preparedness requirements and address potential obsolescence, phase out demand and discontinued supply issues; despite the fact that the fleet has a looming end of service life date. However, the desire not to over invest in inventory as an asset approaches the end of service life is balancing against these needs, as this can tie up financial resources and potentially add to labour, warehousing, transport and eventual asset disposal costs. These matters create tensions between effectiveness and efficiency considerations as system fleets reach the end of their service life. Past experience often suggest these issues are a secondary consideration in fleet management.
\end{abstract}

This paper will explore a range of end of service life logistic issues including approaches to the inventory management functions of requirements determination, and replenishment planning. We will consider some standard approaches to these functions and highlight how end of service life considerations may require new management heuristics and process models. In particular, we investigate efforts to integrate a spare parts management (SPM) phase out strategy. This includes seeking a process for developing options, and goal setting the final state of the spare parts inventory at the asset's end of life date. This can then modify demand forecasting selection processes and calculations for replenishment actions. Importantly, inventory segmentation can play a role to determine how to treat various asset spare parts based on factors such as supply characteristics, demand, cost, stock on hand and relationships to other parts of the asset sustainment system. How these factors can be integrated into a management model for decision policy is a focus of our discussion. We then present a management process model to indicate which replenishment actions suit particular items in the inventory based upon phase out segmentation analysis and a desired end of service state. In doing so, a number of key end-of-service life policy options can be proposed. This can aid military planners to oversee inventory management of assets that are approaching end of life.

Keywords: $\quad$ Spare parts management, segmentation, phase out, end-of-life, replenishment 


\section{INTRODUCTION}

This paper focuses on SPM in the End-Of-Life (EOL) phase of a spare part life cycle for land military fleets. We concentrate particularly on the situation where spare parts are mostly available for ordering, but service obligations are approaching phase out. In this case, if the quantity of spares is insufficient, the fleet faces stock out costs and vehicle unavailability. On the other hand, if the inventory is overstocked, at the end of EOL phase Defence must dispose of or on-sell of extra parts, which also causes extra costs.

As the EOL phase is often the most unpredictable in a demand sense, the final re-ordering (last time buy LTB) of spare parts sizing becomes problematic. This problem is called the final order problem; we can extend this problem to include adjustments to subsequent reorders that are affected by EOL and call it the phase out ordering problem.

\section{THE SUPPLY CHAIN MANAGEMENT AND DISPOSAL ENVIRONMENT}

There are many stakeholder roles involved in providing any input to a SPM strategy addressing the phase out ordering problem. Lifecycle managers, demand and supply planners often will rely on the work of inventory management modelling analysis. Analysts in inventory management tend to concentrate on quantifiable measures; these measures should relate back to the underlying objectives in SPM. Unfortunately many overarching objectives are difficult to quantify such as navigating political and contractual restrictions (within and outside Defence) and keeping the amount of human effort in the planning and operation of decision making to an acceptable level. Part of an SPM strategy should aim to alleviate some of these objectives by outlining a clear process in such decision making.

A successful SPM strategy implies the availability of the right type of parts in the right quantity at the right time. Often the key element to successful procurement is spare part demand forecasting. Other relevant inputs include unit item costs (for e.g. procurement, warehousing and disposal), internal requirements (such as $95 \%$ service level) and lead time for parts availability. There is a drastic difference between strategies that utilize reordering and those that do not. For most of the fleet parts demanded, the service contract of the related product lasts longer than the EOL. Therefore, at some point, Defence should decide in most cases when there is a last opportunity to order spare parts. After the LTB date, ordering is not undertaken in any usual means and inventory level can only decrease, unless the inventory is recovering (reparable items). Another EOL consideration is the disposal and salvaging process itself.

There exist several software products such as OPUS (from Systecon) and SAP (Systems, Applications, and Products in Data Processing, see Dickersbach 2007). that are often used for sparing assessments in support of capital acquisitions. There are caveats to this software that could be applicable to aspects of the phase out problem such as when resetting stock-levels - using OPUS or determining phase out profiles in SAP. There is however usually workload overhead and data remediation issues associated with using such software. Lack of data can make them unworkable; however they can be a useful tool particularly when resetting stock levels for the fleet. Often in these cases simpler calculations can offer solutions such as those mentioned in Johnson (1962), Popp (1965), Naddor (1966), Brosseau (1982), Tavares \& Almeida (1983) and Rosenfield (1989).

\section{THE PHASE OUT ORDERING PROBLEM FOR MILITARY FLEETS (OVERVIEW)}

First the key questions of logistic control in phase out ordering are presented. Fortuin and Martin (1999) state that four important questions for controlling spare parts should be answered: Which items are needed as spare parts? Which spare parts have to be stocked? When do we need to (re)order? How much do we need to (re)order? These questions need to be answered in pre-empting viable solutions to the phase out ordering problem. In reaching such solutions a SPM phase out ordering strategy is needed. In this section we overview a heuristic approaches to such a strategy. We partition the SPM strategy into seven processes:

1. Data collection, remediation and augmentation

2. Segmentation of inventory (without EOL considerations)

3. Revaluing cost calculations for the phase out problem

4. Assessing changes to demand and supply behaviour

5. Re-segmenting the inventory with adjustment for phase out problem

6. Finding the desired end of state for the inventory

7. Formulate the phase out replenishment strategy to robustly meet a desired end of state for the inventory. 
The ordering of these processes is shown in Figure 1, with the first 6 processes paired to show the staging of work flow and input requirements.

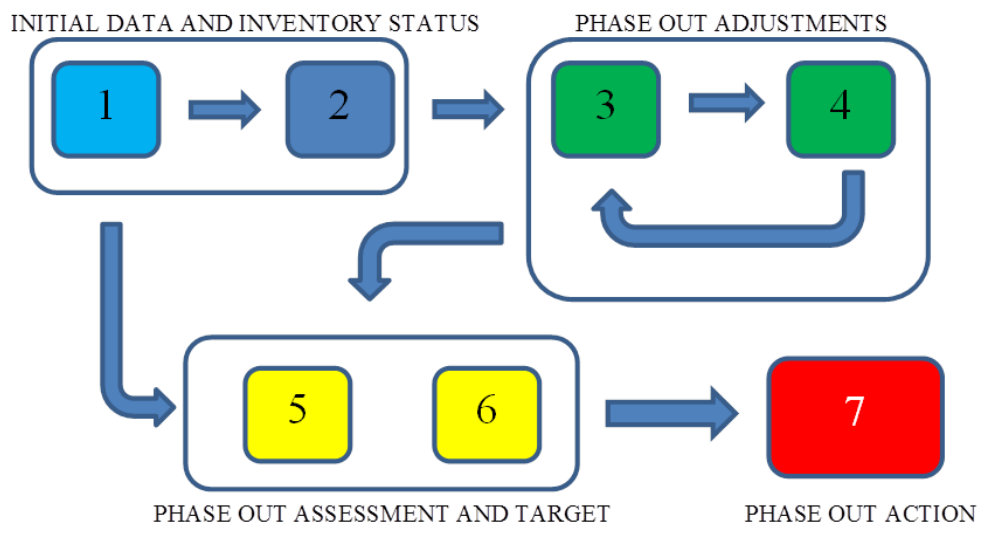

Figure 1. Work flow staging of 7 processes for the SPM phase out strategy

\subsection{Data collection, remediation and augmentation}

The first step on our chain of processes relies upon the collection of data. This data collection should provide input to the other processes. However often there is insufficient or not accurately representative information, which may require augmentation, if possible, to such data to give appropriate input. We can break the data input types into a few groups:

- Costing factors: item cost, carrying cost, salvage costs, stock-out costs, transport costs, disposal costs

- Demand Patterns: requisition quantity/timing and variability, seasonality, inter-dependencies, forecast ability, stock on hand changes, failure rates

- Supply environment: lead times, flexibility, reliability, order sizing and timing, freight volumes and timing, supplier restrictions, repair times, planned maintenance activities

- Nature of product: consumable/perishable, repairable, shelf-life, reclaimable (cannibalisation), substitutable

- Administrative characteristics: timing and quantity of information, local business practices, parts supplier relationships and practises, stakeholder limitations, location information

- End-of-life information: EOS timing, fleet reductions, replacements and operational changes, disposal capabilities.

\subsection{Segmentation of inventory (without EOL considerations)}

An important facet of inventory segmentation is item classification. Item classification can be used in two separate ways. Firstly, it can be used to identify the most critical items needing managers' attention. Military fleets usually have thousands of stock items, and it is clear that all of them cannot be handled individually. Instead, Defence must identify the most critical ones and to concentrate on these. This however has often led to the use of lists of essential items that may not reflect "critical" from a system functioning point of view. Secondly, it is possible to use item classification in procurement more generally based on demand/supply/cost characteristics. Those items that are not slow-moving will rely somewhat on demand profiling for classification and hence forecasting. Any forecast is taken as an input of the procurement process, and classification is used to depart from this forecast when needed. However, most items in military fleets are slow-moving and show little historical demand. A suitable approach to known demand indicators qualitative forecasting, risk and gauging current stock on hand are more relevant in this case.

There are several factors that are used to segment the inventory by item classification. We call these factors segmentation subjects. The most obvious, and in many cases most important, segmentation subject is cost. This can incorporate the item price, inventory cost (storage and movement), key price (associated costs with repair) and stock-out cost. Another subject is lead time for service (time it takes to request an item til item is in service); long lead times can cause delays in maintenance which then can change the demand of other inventory items as well as increasing stock out costs through possibly unavailable vehicles. For example low 
cost items by (price, inventory and key) can be bought well above forecasted demand if the stock out cost is not low, particularly if they are fast movers and vulnerable to variation in lead time and demand. An item with long lead time may require considerable safety stock due to slow responsiveness to variation in demand. Another issue is the nature of the variability in the demand. SPM for Defence is often categorised as "lumpy", a term used to describe erratic (in demand quantity) and intermittent (in terms of demand timing). The very nature of this variability makes it difficult for forecasting to accurately predict future demand. Other issues that are considerations include: limited shelf life, returning items, data remediation issues, shared parts with other fleets, associated parts (kits/common arrangements for a maintenance task).

To undertake segmentation we need to take the above factors into account in a structured way. For each item we can list the segmentation subjects and use descriptors about them as classifications as shown in Table 1. Then using these classifications we cluster like or associated items, this will help us inform what replenishment action to recommend for each item's stocking until EOL.

Table 1. Potential segmentation subjects and descriptors for classifying items

\begin{tabular}{|l|l|l|l|}
\hline Segmentation subjects & Classifications (descriptors) & Segmentation subjects & Classifications (descriptors) \\
\hline Cost (requisition) & \$ amount & Demand Variability type & Seasonal/lumpy/erratic/none \\
\hline Cost (storage and transport) & \$ amount per unit time or km & EOL demand adjustment & Normal/linear/decay/cease/uncertain \\
\hline Cost (associated repair) & \$ amount & Inventory position & Well above requirement/low \\
\hline Cost (disposal) & Net \$ amount (options based) & On hand stock (historical) & Well above requirement/low \\
\hline Cost (system unavailability) & $\begin{array}{l}\text { \$ amount or subjective } \\
\text { suggestion }\end{array}$ & Substitutable item & $\begin{array}{l}\text { Yes/temporary/no/Additive } \\
\text { Manufacturing }\end{array}$ \\
\hline Demand & Low to high & Reclaim access & No/Difficult/easy \\
\hline Requisition frequency & Low to high & Essentiality (stand-alone) & Low/high \\
\hline Lead Time & Short to long & Associations of part & $\begin{array}{l}\text { Yes/no/kit number/part } \\
\text { cluster/shared item }\end{array}$ \\
\hline Lead Time Demand & Low to high & Repairable/perishable & Yes/no \\
\hline
\end{tabular}

\subsection{Revaluing cost calculations for the phase out problem}

There are generally three major adjustments to replenishment cost-benefit considerations in the phase out period:

- adjustments to supply (e.g. reduced replenishment quantities could increase per unit cost) and inventory costs (say larger last time buys and redistribution costs),

- diminishing value (reduction in stock out costs) in reordering as a result of looming EOL date,

- $\quad$ And the disposal/salvage costs accrued by excess stock at EOL.

In the case of large military fleets most items should still be globally available; this suggests that there is less likelihood of significant changes to item price, however there may well be more or less inventory costs to consider. The delivery systems and distribution of spares in time may become sparser and in so increase logistical costs to obtain items.

There are restrictions on some military fleet's parts which preclude or restrict on-selling, or are of no use to commercial enterprise. Shared parts however may only require a minor adjustment to stocking particularly if the fleet contributes only a small amount to overall demand. Generally the options for excess stock are: use for other purposes, shipment to another location, sales to foreign partners, return to supplier, auctioning and scrap. These factors can contribute to determining options and a value for net salvage cost when considering how much stock to retain for disposal calculations. In order to be able to estimate stock-out costs, the following questions have to be answered each time a final order is placed: Does the component render the vehicle non-functional? Is there a substitute part in case the component is not in ready supply? Are there any knock on effects upon other parts usage/failure (by association)? If the answer to one of the first two questions is 'yes' then the final order must be small. If the answer to all three questions is 'no' then the final order should be large, since the only alternative in case of a stock out is to offer the customer a new item. Some items particularly those with long lead times and high cost may have little value in being reordered if the estimated time of usage is minimal.

\subsection{Assessing changes to demand and supply behaviour}

When forecasting regular data, the choice of forecasting algorithm can often result in significant improvements. When solving the phase out order problem, traditional forecasting algorithms may not be applicable. When the life cycle phase changes, the statistical algorithms used for forecasting, may be unable 
to follow the changing pattern. Therefore, the improvements stem from adding available information to the forecast, not from the technical tuning of algorithms. Such information can include the effect of asset failure rate growth in time (wear-out effect) and cause parts demand to grow.

Besides using historical demand directly, another approach to the SPM phase out order problem is that of calculating the failure rates for spare parts (failures per year for instance), Sherbrooke (1968). That is, multiplying the amount of parts in use with an estimate of usage rate and using the result as a further forecast. This approach is heavily dependent on the reliability of the usage rate: even a small change in the rate can lead to huge differences in final order amount. A common effect is that of failure rate growth in time (wearout effect) and hence causing demand to become even higher.

Factors such as estimated horizon service time in relation to lead time are important here. Cattani and Souza (2003) consider the advantages of delaying LTB, i.e. the consequences if the possibility for reordering is extended. They conclude that delaying is beneficial and that the benefits of delay are non-decreasing and concave in delay time. In other words, longer delay is never worse than shorter delay and that most benefits are obtained early. The results are intuitively logical: the longer we delay the LTB, the more accurate we can forecast the phase out demand and the possible risk of obsolescence or shortage diminishes. The decision to ignore a phase out demand pattern should occur with items that are characterised by a short lead time. However long lead-time restrictions can compromise such delay benefits and an earlier LTB may be required.

There are some common estimated phase-out reduction demand patterns ${ }^{1}$ in the literature. The case of setting a demand profile to zero will occur when items have high stock levels with low demand or those with no recent demand. There are variations and analysis of exponential methods initially by presented by Ghare and Schrader (1963) that can be found in early literature by Smith (1977), Hollier and Mak (1983), Cheng (1989), Dave (1991) and then again by Hill, Omar and Smith (1999). Likewise there are linear methods presented in Donaldson (1977), and Brosseau (1982). There is also a SAP software phase out planning tool that estimates phase out demand using options for upper bounds on forecasts, exponential decay and error correction.

\subsection{Re-segmenting the inventory with adjustment for phase out problem}

As discussed earlier there are many issues that determine suitable segmentation of inventory for replenishment and there are further considerations with phase out. One of the key pieces of information in this process is the stock on hand $(\mathrm{SOH})$ and their location. SOH can have several interpretations (net stock, inventory position, on-hand stock); Silver, Pyke and Peterson (1998) give a description of these. For many stock items the aggregate $\mathrm{SOH}$ will be greater than the foreseeable demand for the remainder of the service horizon. We can consider SOH to be high when the current inventory position is well above anticipated demand until EOL, low when the current inventory position is negative, and dispersed if the on-hand stock is widely spread over a distribution network that causes additional delays to satisfying demand. Historical onhand stock is also important if there have been no recent requisitions. If, say, on-hand stock estimates from some previous point in time may help indicate that the lack of requisition is due to previous high stock levels being diminished, rather than no usage, and may indicate that further requisition is needed before EOL.

Anticipated changes to the costing, demand and supply behaviour should be applied to the earlier segmentation technique to redefine item characteristics. Timing can influence a draw down in the requisition of items with long and uncertain lead times. Parts may not arrive until close or after the EOL and therefore not to be of much benefit to the fleet. Firstly for slow moving items a decision needs to be made on whether to allow requisition or even continue to stock items. Other item characteristics also come into consideration during the phase out period particularly in regard to temporary compromises. This includes the ability to substitute availability/suitability of non-OEM parts at risk of failure and the ease at which an item can be removed from one vehicle and used on another (reclaimable item) for an acceptable loss in availability.

\subsection{Finding the desired end of state for the inventory}

The determination of the desired end of state (or end of states) generally can be thought as a risk problem often represented through a cost minimisation approach. The option base depends on many factors such as disposal costs and processes, on-sell opportunities, storage and freight costs, materiel hazards and timing uncertainties in the phase out period. There are cases when compromise on the cost against availability in the

\footnotetext{
${ }^{1}$ In this paper will refer to both exponential and linear methods as collections of demand patterns, many of the reference material also provides replenishment action models that complement these demand patterns.
} 
phase out period is also an option whereby a small amount of stock out (and unavailability) is accepted. This in turn can be useful in determining estimates for EOL SOH. Generally though, EOL SOH is intended to be low or zero for most cases except where there is a gain to be made by the on-sell value, or there is value in stock being in a particular location (for on-sell or disposal/storage reasons).

\subsection{Formulate the phase out replenishment strategy to robustly meet a desired end of state for the inventory}

The ultimate goal of the previous processes is to inform what action needs to be taken for the actual replenishment in the SPM phase out period. The range of replenishment actions for items can be put into the categories outlined in Table 2. The right most column of this table gives reference to either literature that provides background material for decision making, analytical/numerical solutions and/or software that is used for developing models formulating a replenishment action.

Table 2. List of replenishment actions

\begin{tabular}{|l|l|l|}
\hline Replenishment actions & Description & Reference to models (examples) \\
\hline Continue as normal & $\begin{array}{l}\text { The current or usual replenishment action continues with no } \\
\text { impact until EOL }\end{array}$ & Continue as already \\
\hline $\begin{array}{l}\text { Do not stock, begin } \\
\text { disposal/transfer }\end{array}$ & $\begin{array}{l}\text { No longer accept requests for more stock and begin disposing of } \\
\text { stock on-hand }\end{array}$ & $\begin{array}{l}\text { Johnson (1962), Popp (1965), } \\
\text { Tavares \& Almeida (1983) }\end{array}$ \\
\hline $\begin{array}{l}\text { Do not stock and await } \\
\text { flag for disposal/transfer }\end{array}$ & $\begin{array}{l}\text { No longer accept requests for more stock and await timed } \\
\text { instruction for disposing of stock on-hand }\end{array}$ & Naddor (1966) \\
\hline Delay requisitions & Await timed instruction for further requisitions & Cattani and Souza \\
\hline Delay any LTB & Await timed instruction and collect data to inform a last time buy & Cattani and Souza \\
\hline Re-allocate stock & Move stock across locations to reduce stock-out/disposal risks & OPUS \\
\hline Adjust ROP/ROQ values & $\begin{array}{l}\text { Use the changing demand and supply conditions to create) adjusted } \\
\text { ROP/ROQ quantities }\end{array}$ & $\begin{array}{l}\text { SAP, Exponential \& Linear } \\
\text { methods }\end{array}$ \\
\hline $\begin{array}{l}\text { Adjust ROP/ROQ values } \\
\text { and begin disposals }\end{array}$ & $\begin{array}{l}\text { Use the changing demand and supply conditions to create adjusted } \\
\text { ROP/ROQ quantities and begin disposing of excess stock. }\end{array}$ & $\begin{array}{l}\text { Naddor (1966), SAP, Exponential } \\
\text { methods \& Linear methods }\end{array}$ \\
\hline $\begin{array}{l}\text { Formulate a LTB } \\
\text { Prepare a final requisition }\end{array}$ & $\begin{array}{l}\text { Tavares \& Almeida (1983), } \\
\text { Rosenfield (1989) }\end{array}$ \\
\hline $\begin{array}{l}\text { Reset stock levels to new } \\
\text { values }\end{array}$ & $\begin{array}{l}\text { Use a tool to reset stock to new values; make disposal or } \\
\text { requisitions based on suggested inventory positions. }\end{array}$ & OPUS, Sherbrooke (1968) \\
\hline
\end{tabular}

The penultimate aim is to then utilise the re-segmentation of the inventory and EOL desired state to aid in determining the replenishment action(s) for various items. In Table 3 we present a simplified example of the process, whereby the re-segmentation description flags possible aspects about 10 items from 5 segmentation subjects; cost, demand level, demand uncertainty, lead time and SOH. There are also four EOL desired states for the number of items in the inventory; any value, low/zero, determined by location or based on on-sell profit. For each item a replenishment action is determined by the re-segmentation description and the items inventory EOL desired state.

Table 3. Examples of mapping re-segmentation categories and EOL desired state to Replenishment actions

\begin{tabular}{|l|l|l|l|}
\hline Item & Re-segmentation description & EOL desired state & Replenishment action \\
\hline 1 & Low-cost, high demand, short lead time & Any value & Continue as normal \\
\hline 2 & SOH too high, low demand & Low/zero & Do not stock, begin disposal/transfer \\
\hline 3 & Low demand & Low/zero & Do not stock and await flag for disposal/transfer \\
\hline 4 & Intermittent demand & Low/zero & Delay requisitions \\
\hline 5 & High cost, uncertain demand & Low/zero & Delay any LTB \\
\hline 6 & Dispersed SOH, low demand & Location specific & Re-allocate stock across locations \\
\hline 7 & High cost, long lead time & Low/zero & Adjust ROP/ROQ values \\
\hline 8 & High cost, long lead time, & On-sell value & Adjust ROP/ROQ values and begin disposals \\
\hline 9 & High SOH, short lead time, high cost & Low/zero & Formulate a LTB \\
\hline 10 & Low SOH, known demand changes, & On-sell value & Reset stock levels to new values \\
\hline
\end{tabular}

This method shown can be extended for a larger set items, possible re-segmentation descriptions (through segmentation subjects and classifiers) and EOL desired state combinations. Using historical information from past fleet phase out events this process can be simulated to generate suitable options for replenishment actions based on this method. 


\section{CONCLUSION}

The paper presents an inventory management process to indicate the suitability of types of replenishment models to use during phase out. The key aspect of this process is the segmentation of items based upon adjustments for phase out behaviour and finding options for the desired EOL state. Such segmentation takes into consideration assessments made to anticipate changes to cost calculations, demand and supply. This all relies on the data collection, remediation and augmentation to support the segmentation processes. Segmentation format, the list of subjects and classification descriptors can be expanded (or contracted) to suit a particular inventory size and features. The process model could aid Defence sustainment by providing a template for a phase out tool development that can guide inventory managers in preparing inventories for planned phase out of assets.

\section{REFERENCES}

Brosseau, L.J.A., 1982. An inventory replenishment policy for the case of a linear decreasing trend in demand. INFOR 20, 252 \pm 257 .

Cattani, K. D. and Souza, G. C. (2003). Good buy? delaying end-of-life purchases. European Journal of Operational Research, 146:216-228.

Cheng, T.C.E., 1989. Optimal production policy for decaying items with decreasing demand. European Journal of Operational Research 43, 168 \pm 173 .

Dave, U., 1991. A discrete-in-time deterministic inventory model for items with decreasing demand. Cahiers du C.E.R.O. 33, $183 \pm 193$.

Dickersbach, Jorg T. Supply Parts Planning with mySAP SCM, Springer Verlag, Berlin Heidelberg, 2007.

Donaldson, W.A., 1977. Inventory replenishment policy for a linear trend in demand \pm an analytical solution. Operational Research Quarterly 28, 663 \pm 670 .

Fortuin, L. and Martin, H. (1999). Control of service parts. International Journal of Operations\& Production Management, 19(9):950-971.

P. M. Ghare and G. H. Schrader, “A Model for Exponen- tially Decaying Inventory Systems,” International Jour- nal of Production and Research, Vol. 21, 1963, pp. 449- 460.

Hill, R. M., Omar, M. and Smith, D. K. Stock replenishment policies for a stochastic exponentially-declining demand process. European Journal of Operational Research,v. 116, p. 374-388, 1999.

R. H. Hollier and K. L. Mak, "Inventory Replenishment Policies for Deteriorating Items in a Declining Market," International Journal of Production Research, Vol. 21, No. 6, 1983, pp. 813-826. doi:10.1080/00207548308942414

Johnson J. (1962). On Stock Selection at Spare Parts Stores Sections. Naval Research Logistics, 9(1), 45-49-

E. Naddor, Inventory Systems, Wiley, New York, 1966.

Popp, W. Simple and Combined Inventory Policies, Production to Stock or to Order. Management Science, v. 11-9, p. 868-873, 1965.

Rosenfield, D. B. (1989) Disposal of Excess Inventory. Operations Research, 37(3), 404-409.

Sherbrooke, C. C. (1968). Metric: A multi-echelon technique for recoverable item control. Operations Research, 16(1):122-141.

Silver, E.A.; Pyke, D.F.; Peterson, R. (1998). Inventory management and production planning and scheduling. 3rd edition. Wiley, Chichester. ISBN 0-471-11947-4

Smith, P.H., 1977. Optimal production policies for items with decreasing demand. European Journal of Operational Research 1, 365 \pm 367 .

Systecon AB. OPUS10 - Algorithms and Methods. Version 10.0, 2014.

Tavares, V \& Almeida L. T. (1983). A Binary Decision Model forthe Stock Control of Very Slow Moving Items. Journal of Operational Research Society, v. 34-3, p. 249-252, 1983. 